ISSN electrónico: 2602-8069

\title{
MONITOREO RÁPIDO DEL USO DE PLATAFORMAS \\ TURÍSTICAS ASOCIADA A ESPACIOS DE APRENDIZAJE- COMUNICACIÓN CULTURAL: CASO DE ESTUDIO MUSEOS (ECUADOR).
}

\section{Fast Monitoring the use of tourist plataforms associated with cultural learning-comunication spaces: case study museums (Ecuador)}

\author{
Gómez Edwin \\ Universidad Central de Ecuador. \\ edgomez@uce.edu.ec \\ Preciado Solange \\ Universidad Central de Ecuador. \\ solangepreciado@gmail.com \\ Palma Verónica \\ Universidad Central de Ecuador. \\ vero_patty.v@hotmail.com \\ Chumaña Tania \\ Universidad Central de Ecuador. \\ tcchumana@uce.edu.ec \\ Arrivillaga-Henríquez Jazzmín C. \\ Universidad Central de Ecuador. \\ jcarrivillaga@uce.edu.ec
}




$$
\begin{gathered}
\text { Gómez Edwin - Preciado Solange - Palma Verónica - Chumaña Tania - Arrivillaga } \\
\text { Jazzmín } \\
\text { Monitoreo rápido del uso de plataformas turísticas asociada a espacios de } \\
\text { aprendizaje-comunicación cultural: caso de estudio museos (Ecuador) }
\end{gathered}
$$

\section{RESUMEN}

Los museos de la ciudad de Quito están asociados a la plataforma de oferta pública de la Fundación Museos de la Ciudad-Sistema de Museos y Centros Culturales de Quito. Los museos, Museo Casa de Sucre/Museo defensa y el Museo de Arte e Historia Alberto Mena Caamaño/Museo de Cera son promocionados desde la plataforma tecnológica de la red de museos. El objetivo del presente trabajo fue monitorear el grado de conocimiento, percepción y satisfacción de los visitantes/usuarios sobre las plataformas que permiten el acceso digital a estos museos, para lo cual, se aplicaron cuestionarios individuales dirigidos a los visitantes de los museos para determinar la tendencia en la opinión del visitante-usuario. Adicionalmente, se evaluaron las páginas web de los museos según evaluación de comunicación y eficacia. Los resultados evidencian que las plataformas son de tipo 1.0 con un contenido para un público en general, pero que no permite la gestión del conocimiento cultural histórico efectivo por parte del visitante-usuario. Se concluye que los museos requieren implementar estrategias alternativas para el uso de redes sociales, las que permitan no solo la consulta de contenidos específicos, sino también la construcción del conocimiento de forma participativa e interactiva que logre un aprendizaje efectivo por parte de la comunidad local e internacional, y así poder proyectarse con inmediatez hacia una verdadera comunicación web 2.0, lo que facilitará corto plazo incorporarse a las tendencias actuales de comunicación web 3.0.

Palabras clave: Museo, web 2.0, aprendizaje, turismo cultural, red social

\section{ABSTRACT}

The city museums of Quito are associated with the public offering platform of the Museums of the City Foundation - Quito's Museums and Cultural Centers System. The museums, Casa de Sucre Museum / Defense Museum and the Alberto Mena Caamaño Art and History Museum / Wax Museum are promoted from the technological platform of the museum network. The objective of this work was to monitor the degree of knowledge, perception, and satisfaction of visitors/users on the platforms that allow digital access to these museums, for which individual questionnaires were applied to museum visitors to determine the trend in visitor-user opinion. Additionally evaluate the webites of the museums according to communication and effectiveness evaluation. The results show that the platforms are of type 1.0 with a content for a general public, but that does not allow the management of effective historical cultural knowledge by the visitor-user. It is concluded that museums require strategies for the use of social networks that allow not only the consultation of specific contents but also the construction of knowledge in a participatory and interactive way that achieves effective learning by the local and international community, and thus be able to project with immediacy towards a true web 2.0 communication, which will facilitate short term incorporation to the current web communication trends 3.0.

Key words: Museum, web 2.0, learning, cultural tourism, social network 


\section{Gómez Edwin - Preciado Solange - Palma Verónica - Chumaña Tania - Arrivillaga Jazzmín \\ Monitoreo rápido del uso de plataformas turísticas asociada a espacios de aprendizaje-comunicación cultural: caso de estudio museos (Ecuador)}

\section{INTRODUCCION}

El poder de atracción de un espacio turístico está directamente relacionado con la capacidad de difusión de su patrimonio, aspecto vital para el segmento del turismo cultural ya que, el turista cultural suele ser un gran consumidor de información en las fases de anticipación, experiencia y recreación del viaje turístico (Mallor et al., 2013).

El turismo no solamente se encuentra enfocado en el movimiento de masas o movilidad humana de un destino a otro, sino incluye el aprendizaje de diferentes culturas del mundo, asociado a las nuevas tendencias de la demanda de los turistas y visitantes, quienes buscan conocimiento y saberes durante la visita o estadía al destino o atractivo turístico con valor histórico cultural (Alfonso, 2003).

Las TIC (Tecnologías de la Información y las Comunicaciones) son actualmente una herramienta clave para la difusión del patrimonio histórico cultural que, junto a los canales web convencionales, y a las nuevas herramientas de la Web 2.0 (redes sociales), han permitido la socialización de la tecnología móvil, lo cual logra que el público en general pueda contar con soportes o plataformas digitales de prestaciones de servicios que posibilitan el uso de servicios de geolocalización, así como acceder a bases de datos e incluso implementar sistemas de realidad aumentada, lo que facilita socializar y gestionar el conocimiento (Sánchez, 2010; Caro et al., 2014).

Específicamente, las TIC marcan una pauta importante, en la difusión y reputación en línea de los destinos turísticos, creándose un marco de referencia que debe ser atendido con fines de comunicación masiva, apoyado en las redes sociales (Medina y Plaza, 2015; Márquez-González y Herrero, 2017, Miranda, 2017)

En los últimos años se ha producido un gran avance en cuanto al uso de las redes sociales como un medio para generar y transmitir información al turista. En vista de la gran acogida por parte del turista, al poder conocer algún destino o atractivo turístico por medio de plataformas tecnológicas, muchos espacios públicos de interés cultural se han modernizado creando plataformas con contenido turístico con fines de promoción y marketing (Mendes et al.,2013).

En la última década, el internet se ha introducido en los sectores turísticos, con énfasis en la creación de plataformas didácticas, en la que los museos se han visto favorecidos con la creación de museos virtuales, en donde desde la comodidad del hogar se puede conocer el contenido del museo, favoreciéndose la gestión del conocimiento cultural de una forma más efectiva en una era digital, y su vez incrementado el nivel de satisfacción del visitante, reflejo del compromiso de la gestión turística (Castillo Alfaro, 2012; Quinteros, 2015).

Los museos que forman parte de una red, como parte de la oferta pública, básicamente su promoción esta mediada por lo entes gubernamentales, quienes con la plataforma pública dan a conocer los diferentes contenidos de los museos de la red, buscando atraer al público joven, el cual está cada vez más ligado a la tecnología, y especialmente asociado a las redes sociales, alcanzándose un nuevo tipo de segmento interesado en estos centros culturales (Baños, 2013).

En los últimos años, conforme aumenta la valoración social de las nuevas tecnologías, la tendencia en algunos museos se ha enfatizado en el uso de medios de difusión con aplicaciones interactivas para dispositivos móviles, redes sociales, foros, blogs, etc. (Celorrio, 2015). Así, la tecnología digital podría ayudar considerablemente a estos museos en su rol educativo al facilitar el acceso a contenidos específicos, reducir sus costos, y dar identidad nacional bajo una visión nacional e internacional, y así ampliar el tiempo de vida de las colecciones (Orozco, 2005). 


$$
\begin{gathered}
\text { Gómez Edwin - Preciado Solange - Palma Verónica - Chumaña Tania - Arrivillaga } \\
\text { Jazzmín } \\
\text { Monitoreo rápido del uso de plataformas turísticas asociada a espacios de } \\
\text { aprendizaje-comunicación cultural: caso de estudio museos (Ecuador) }
\end{gathered}
$$

\section{MARCO TEÓRICO}

\section{Plataformas turísticas y destinos culturales}

Así como en muchos sectores, el turismo actualmente depende de la tecnología, la cual ha ido avanzando y ha obligado a los usuarios a optar por esta nueva herramienta, brindándole al turista/visitante usuario la posibilidad de opinar, quejarse, sugerir y comentar sobre un destino turístico o atractivo turístico. Por ende, se puede hablar de una nueva forma de viajar en la cual se pretende organizar dichas experiencias con base en comentarios emitidos por otros turistas/visitantes que han estado en el mismo lugar de interés de visita, permitiendo generar mayores conocimientos para los futuros viajeros. En la actualidad, las plataformas tecnológicas y las redes sociales permiten la conectividad entre el usuario y el destino turístico, el cual puede ser cultural. De esta manera, se promociona un destino cultural y sus atractivos asociados creando una imagen como producto turístico. En estos sitios Web se puede encontrar contenidos históricos, patrimoniales y culturales que permiten el posicionamiento turístico determinado por la afluencia de usuarios digitales y por el tráfico de los contenidos en la comunidad de seguidores en pro de activar las visitas en los destinos y atractivos culturales (Sánchez, 2010).

\section{Plataformas turísticas y museos}

En 2007, el Consejo Internacional de Museos (ICOM), aprobó la siguiente conceptualización para los museos: "El museo es una institución permanente, sin fines de lucro, al servicio de la sociedad y abierta al público, que adquiere, conserva, estudia, expone y difunde el patrimonio material e inmaterial de la humanidad con fines de estudio, educación y recreo".

Por lo que hoy en día la promoción o marketing de los destinos culturales está en auge, en donde los museos representan los atractivos turísticos de primera elección por parte de los turistas/visitante, constituyéndose los museos como recursos claves en la planificación y gestión turística cultural en pro del desarrollo local de un destino, siendo incluidos en las de rutas y paquetes turísticos. Sin embargo, son pocos los museos que se encuentran saturados de visitantes, lo cual ha promovido el uso de estrategias de promoción turística para los museos con base en plataformas tecnológicas que generen contenidos e información actualizada, verídica, interactiva y participativa con el turista/visitante que tiene requerimientos, necesidades y motivaciones de viaje culturales. De esta manera, en la actualidad, las personas que van a los museos lo hacen por referencia de otras personas, amigos y parientes, lo que evidencia la necesidad de mantener fieles visitantes y usuarios recurrentes de las plataformas tecnológicas y redes sociales propias de los museos, incluyendo las plataformas colaborativas entre museos que trabajan en equipo para mantener al público "enganchando" a los productos turísticos culturales de los museos participantes (Fernández, 2015).

Estas estrategias digitales adoptadas por los destinos culturales, ha incrementado la valoración social de las nuevas tecnologías asociada a los museos permitiendo la difusión cultural, y ante este desarrollo tecnológico, los museos han visto en la tecnología digital una alternativa para cumplir su rol educativo como espacio de aprendizaje y comunicación cultural, mejorando la accesibilidad a los contenidos culturales, dándole a la identidad nacional una dimensión internacional mediada por las redes sociales (Celorrio, 2015). 


$$
\begin{gathered}
\text { Gómez Edwin - Preciado Solange - Palma Verónica - Chumaña Tania - Arrivillaga } \\
\text { Jazzmín } \\
\text { Monitoreo rápido del uso de plataformas turísticas asociada a espacios de } \\
\text { aprendizaje-comunicación cultural: caso de estudio museos (Ecuador) }
\end{gathered}
$$

\section{Museos, contenidos culturales y plataformas tecnológicas}

Tradicionalmente, los museos han generado sus contenidos culturales mediante los departamentos de difusión cultural, quienes se han encargado de los procesos de transferencias de conocimientos culturales, facilitando la accesibilidad de estos a la sociedad, mediada por la publicidad. Sin embargo, en la actualidad, la publicidad en los museos se ha convertido en mercadeo de contenidos a través de internet, redes sociales como medio de comunicación masiva digital, lo que ha permitido que algunos museos gestionen el patrimonio, la historia y la cultura mediante lenguajes digitales que buscan el posicionamiento de los museos en las plataformas tecnológicas desde la visión de marketing digital, planificada por los departamentos de comunicación de los museos. No solo en búsqueda de la comercialización de un producto turístico cultural, sino para el logro de la comunicación corporativa del museo, como un espacio público de aprendizaje y comunicación cultura en pro de la cultura ciudadana y educación de la sociedad a escala local, regional, nacional e internacional, y en especial cuando el atractivo cultural tiene valor turístico. Estos cambios de visión de la publicidad del museo al marketing de contenidos culturales ha derivado de las exigencias y críticas de los usuarios digitales a la publicidad en sí, permitiendo que los museos puedan alcanzar objetivos comunicacionales (Mateos, 2013), en donde el actor principal, el visitante-usuario, de las plataformas digitales no solo desea conocer los contenidos, sino también participar e interactuar en los procesos de creación de los contenidos culturales de una forma dinámica (Gómez, 2013).

En estos procesos de dinamismo tecnológico, los museos han cambiado la forma de comunicar desde el uso de plataformas tecnológicas 1.0, 2.0 y 3.0 La comunicación vía Web 1.0 se centro en la presencia de los museos con contenidos informativos y publicitarios que definían la comunicación con carácter unidireccional dirigido solo a un público general no segmentado y sin posibilidad de retroalimentación, con la finalidad de incrementar el número de visitas en los museos, usando las plataformas como una herramienta de exposición de contenidos, ya que las personas simplemente estaban conectadas a la red. Posteriormente, la oferta en la red asociada a contenidos y servicios tanto para la audiencia off-line y on-line, permitió una primera aproximación a la segmentación del público, y enriqueció la interacción y participación bidireccional con el visitante-usuario de las plataformas tecnológicas, permitiendo una verdadera presencia de los museos en las redes sociales, introduciéndose el concepto de la Web 2.0, ya que las personas están conectadas a otras personas en la red social, permitiendo entonces compartir los contenidos culturales (Asensio et al., 2012b).

En la actualidad, existe la necesidad de tener un rol protagónico por parte del visitante-usuario, es así que se demanda una mayor participación e interactividad, hasta el punto de proponer y modificar contenidos en las plataformas, permitiendo direccionar estrategias tecnológicas nuevas hacia el desarrollo de la Web 3.0 Este sería un un recurso digital en pro de la gestión del patrimonio cultural, con aplicaciones Web interconectadas que facilitarían búsquedas más inteligentes, y con contenidos más significativos para el usuario de plataformas, promoviendo finalmente una comunicación 3.0 (Asensio et al., 2012b). 


\section{Gómez Edwin - Preciado Solange - Palma Verónica - Chumaña Tania - Arrivillaga Jazzmín \\ Monitoreo rápido del uso de plataformas turísticas asociada a espacios de aprendizaje-comunicación cultural: caso de estudio museos (Ecuador)}

\section{Redes sociales y museos participativos}

Las redes sociales se presentan como un sistema de entretenimiento e información. Estos sistemas incluyen herramientas audiovisuales y virtuales, que son incorporadas en la Web 2.0, y permiten crear una plataforma de contenidos la cual ha servido para la comunicación social básica de los museos; esto ha permitido derivar de sus características principales de interactividad, participación y compromiso bajo un concepto de comunidad y comunicación (Campos, 2008; Cabezuela y Martínez, 2010), convirtiéndose en un atractivo con valor no solo cultural sino turístico para los visitanteusuarios (Altamirano, 2017).

El uso activo por parte de los museos de plataformas tecnológica, y en especial de las redes sociales, ha generado en el tiempo una visión de museo participativo e inclusivo, derivado de las tendencias de transformación de los museos en función de la capacidad y creatividad de los visitante-usuarios, es decir, de su público. Esto se extiende hasta el rol cultural participativo de los museos, el cual es apreciado por la sociedad, y en especial por el público visitante. En donde los museos participativos consideran las preferencias e intereses de los visitantes-usuarios para dar una oferta real y ajustada a la demanda, con un objetivo de aprendizaje y de invitación abierta a la colaboración del público en el proceso de gestión patrimonial, histórica y cultural del museo (Fernández, 2015).

En general, los museos se han apoyado en su rol participativo e interactivo en la Web 2.0, principalmente en redes sociales como Facebook y Twitter. Las plataformas 2.0 más usadas para la comunicación digital, en línea y virtual, cuentan con herramientas que permiten la valoración de la participación del visitante-públicousuario (del Río Castro, 2015).

Por lo tanto, los nuevos modelos de gestión cultural por parte de los museos, con visión participativa, requieren monitoreo, seguimiento y evaluación de las plataformas digitales y sus redes sociales, para la planificación y optimización de sus contenidos de aprendizaje y comunicación cultural.

\section{Evaluación de plataformas tecnológicas y redes sociales asociadas a museos}

En general, la planificación y gestión de plataformas tecnológicas y redes sociales requieren de herramientas metodológicas de evaluación como parte de las políticas de comunicación del museo, en donde deben considerarse parámetros de calidad como la accesibilidad, posicionamiento de las web, etc. (Monistrol et al., 2006). En este particular, existen algunos estudios de evaluación cuantitativa de plataformas Web en donde se han evaluado los dominios en función de variables como usabilidad, funcionalidad, eficiencia, mantenibilidad, portabilidad, retroalimentación (Olsina, 1999).

Sin embargo, en relación con la evaluación de Web asociadas a los museos, existen muy pocas investigaciones, las cuales incluyen evaluaciones cualitativas con base en indicadores relacionados con aspectos informativos asociadas a temáticas específicas, análisis de web de idioma, destinatarios, servicios, recursos de navegación, aspectos de comunicación y educativos. Los cuales, han evidenciado el bajo desarrollo participativo e interactivo de los museos en sus plataformas Web 2.0 (Asencio et al., 2012b).

Por otro lado, existen estudios de monitoreo de plataformas tecnológicas y redes sociales de uso oficial para museos, en los cuales se han combinado metodologías cualitativas y cuantitativas para la evaluación de las plataformas turísticas que incluyen al sector cultural (Altamirano y Tuñez, 2016; Tuñez et al., 2016), en donde también se ha evidenciado la baja participación del sector cultural en las redes sociales respecto a otros sectores turísticos. 


$$
\begin{gathered}
\text { Gómez Edwin - Preciado Solange - Palma Verónica - Chumaña Tania - Arrivillaga } \\
\text { Jazzmín } \\
\text { Monitoreo rápido del uso de plataformas turísticas asociada a espacios de } \\
\text { aprendizaje-comunicación cultural: caso de estudio museos (Ecuador) }
\end{gathered}
$$

\section{Situación de las plataformas tecnológicas asociadas a los museos en el Ecuador}

En el Ecuador, el Ministerio de Turismo, a través del sitio web, invita a disfrutar del turismo cultural casi en un $9 \%$ respecto a los contenidos de la página (Altamirano y Tuñez, 2016). Específicamente, algunos estudios relacionados con los museos evidencian que al $44 \%$ de los visitantes le gustaría recibir información vía internet (Jurado, 2015). Sin embargo, solo el $20 \%$ de los museos de la Ciudad de Quito cuentan con páginas web propias, el resto de los museos están asociados a la plataforma pública de museos del Ecuador (solo 13 museos para el 2015 contaban con página web propia, en donde los Museo Casa Sucre y Museo de Cera no estaban en la lista). Adicionalmente, se señala que los museos con plataformas tecnológicas propias tipo web no tienen espacios digitales que permiten acceso a contenido, participación, conocimiento o construcción de saberes (Escandón, 2016). Sin embargo, existen experiencias educativas aisladas relacionadas con espacios de aprendizaje virtuales, como el Museo Virtual Manuela Sáenz (Gordillo, 2014).

\section{Eje de estudio de la investigación}

El eje central del presente trabajo fue realizar un monitoreo rápido como una herramienta gerencial aplicada en la gestión de proyectos en desarrollo en pro de la evaluación de las plataformas turísticas de dos museos pertenecientes al centro histórico de la Ciudad de Quito:, el Museo de la Defensa Casa de Sucre y el Museo de Cera Alberto Mena Caamaño conocido como Museo de Cera. Ambos museos están asociados a la red de museos contenida en la plataforma de la oferta pública, relacionada con la Fundación Museos de la Ciudad- Sistema de Museos y Centros Culturales de Quito. Esto se realizó con la finalidad de verificar la ejecución de actividades o acciones asociadas a los contenidos culturales, y el uso de los recursos TIC por parte del visitante-usuario de las plataformas tecnológicas y principales redes sociales de los museos. Dentro de nuestra hipótesis de trabajo, afirmamos que los museos públicos que no funcionan en redes sociales colaborativas e interactivas utilizan la web 2.0 como plataformas de promoción tradicional al gestionar el patrimonio histórico cultural asociado al museo.

\section{METODOLOGÍA}

\section{Área de estudio}

El área de estudio se ubica espacialmente en el Centro Histórico (sitio con alta afluencia de turista 35,1\%), en donde se evaluaron dos museos. El Museo Casa de Sucre/Museo de Defensa (13\% de visitas) y el Museo de Arte e Historia Alberto Mena Caamaño/Museo de Cera (17\% visitas), los cuales fueron seleccionados por ser de los museos más visitados en la ciudad de Quito según el Ministerio de Turismo del Ecuador. Fig.1. 

aprendizaje-comunicación cultural: caso de estudio museos (Ecuador)

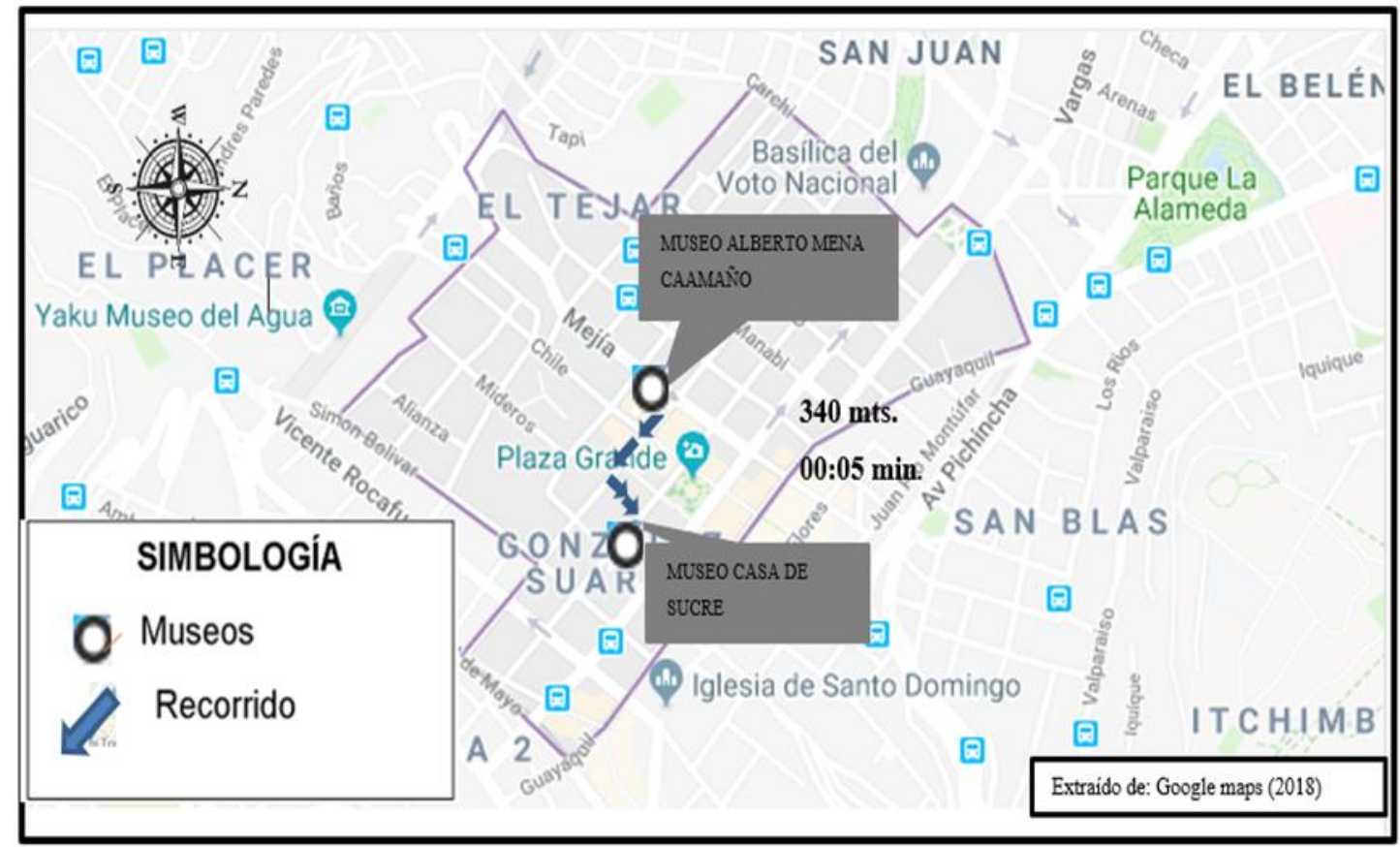

Figura 1. Ubicación espacial de los Museos seleccionados para la investigación

\section{Población y muestra}

Durante el monitoreo rápido, la población de estudio estuvo conformada por los visitantes de los museos con base en una distribución del esfuerzo de muestreo, que implicó la toma de muestras pequeñas a intervalos cortos para estudios cualitativos de casos de estudio bajo un muestreo heurístico y aleatorio (Marshall et al., 2013).

Por lo cual, en los Museo Casa de Sucre y Museo de Cera se seleccionaron visitantes-usuarios de plataformas tecnológicas a quienes se le aplicaron cuestionarios de forma individual (monitoreo de 15 visitantes-usuario x museo x horario matutino ó vespertino) para realizar aproximaciones estadísticas desde los resultados de 30 cuestionarios por cada museo (60 cuestionarios en total), con fines de una evaluación rápida del perfil del usuario en función de cuatro variables (conglomerados) género, edad, nacionalidad y procedencia. Adicionalmente, conocer su opinión respecto al uso de las plataformas tecnológicas.

\section{Monitoreo rápido: Cuestionario aplicado a los visitantes-usuarios}

Se aplicó una evaluación rápida de corte transversal y descriptiva tipo monitoreo durante el mes de febrero 2018, con la finalidad de recopilar, comparar y analizar la información de dos museos seleccionados como casos de estudio, asociados a las plataformas tecnológicas y redes sociales. Mediante el uso de un instrumento de opinión fundamentado en un cuestionario, el cual fue diseñado por los autores. El cuestionario consistió en 10 preguntas cerradas para evaluar el grado de conocimiento, motivación, satisfacción y opinión respecto al uso de plataformas tecnológicas.

Los resultados de los cuestionarios fueron tabulados en una matriz de Excel versión 2010. Los valores obtenidos fueron transformados en porcentajes, con fines de evaluar las tendencias de los datos en función de la variable-pregunta y la opción de elección por el visitante-usuario de la plataforma según el cuestionario a continuación: 
Gómez Edwin - Preciado Solange - Palma Verónica - Chumaña Tania - Arrivillaga Jazzmín

Monitoreo rápido del uso de plataformas turísticas asociada a espacios de aprendizaje-comunicación cultural: caso de estudio museos (Ecuador)

\section{Cuestionario. USO DE LA PLATAFORMAS DE MUSEOS}

Cuestionario N. ${ }^{\circ}$ :

Fecha:

Hora: Museo:

Visitante: Turista: Usuario plataforma-Museo:

Edad: $\quad$ Género: $F$ M Otros

Nacionalidad: $\quad$ Extranjero residente: Si NO

Procedencia: Lugar de habitación:

1. ¿CONOCE LA PLATAFORMA TECNOLÓGICA DEL MUSEO?

Sí NO

ES?

2. ¿CONSIDERA QUE LA PLATAFORMA TECNOLÓGICA DEL MUSEO

Excelente__ Muy Buena___ Buena __ Regular___ Mala

3. ¿QUÉ NIVEL DE SATISFACCIÓN TIENE USTED RESPECTO A LA PLATAFORMA DEL MUSEO?

a) Completamente Insatisfecho

b) Insatisfecho

c) Bastante satisfecho

d) Completamente satisfecho

Nota 1. Indique si Ud. ha OPINADO, COMENTADO, COMPARTIDO algún contenido publicado en la plataforma del museo: $\mathrm{Si} \quad \mathrm{NO}$

Nota 2. Menciones algún comentario que Ud. recuerde haber realizado en la plataforma del museo: MUSEO?

4. ¿CON QUE FRECUENCIA HACE USO DE LA PLATAFORMA DEL
a. Diariamente
b. Semanalmente
c. Mensualmente
d. Anualmente

5. ¿CUÁL FUE EL MOTIVO DE LA CONSULTA VIRTUAL MEDIANTE EL USO DE LA PLATAFORMA DEL MUSEO?
a. Consulta de horarios de visita
b. Observar temarios del museo
c. Otro (Por favor especifique) 
Gómez Edwin - Preciado Solange - Palma Verónica - Chumaña Tania - Arrivillaga Jazzmín

Monitoreo rápido del uso de plataformas turísticas asociada a espacios de aprendizaje-comunicación cultural: caso de estudio museos (Ecuador)

6. ¿CUÁL ES EL PRINCIPAL BENEFICIO QUE SEGÚN UD. SE OBTIENE AL USAR LA PLATAFORMA DEL MUSEO?

a. Facilidad para conocer su oferta

b. Rapidez al realizar reservas

c. Aprendizaje más efectivo de contenidos

d. Otro (Por favor especifique)

\title{
PLATAFORMA DEL MUSEO?
}

7. ¿UD. HA RECIBIDO CAPACITACIÓN PARA EL MANEJO Y USO DE LA

Sí NO

\begin{abstract}
8. SÍ SU RESPUESTA ANTERIOR FUE POSITIVA (SÍ), MEDIANTE QUE PERSONA, PLATAFORMA, CURSO, MUSEO SE CAPACITO ANTES DE PODER ACCEDER A LA PLATAFORMA DEL MUSEO.
\end{abstract}
a. Docente
b. Plataformas tecnologías similares
c. Curso por Internet
d. Museo (personal del museo)
e. Otros (especifique).

\begin{tabular}{|c|c|c|c|c|c|}
\hline & Excelente & $\begin{array}{l}\text { Muy } \\
\text { bueno }\end{array}$ & Bueno & Regular & Malo \\
\hline & 5 & 4 & 3 & 2 & 1 \\
\hline $\begin{array}{l}\text { 9. Clasifique de mayor a menor } \\
\text { importancia } \\
\text { las dificultades encontradas } \\
\text { en el uso de la plataforma } \\
\text { tecnológica del museo }\end{array}$ & & & & & \\
\hline $\begin{array}{l}\text { 10. ¿Cómo calificaría usted las } \\
\text { herramientas virtuales } \\
\text { empleadas en la plataforma } \\
\text { del museo? }\end{array}$ & & & & & \\
\hline
\end{tabular}

Monitoreo rápido: Evaluación de Web de comunicación digital asociada a los museos

Se revisaron los sitios web de la Fundación de Museos de la Ciudad (como referencia para el análisis), Museo de Cera y Museo Casa Sucre como modelos de Web 1.0. Adicionalmente, se revisaron los contenidos de las comunicaciones 2.0 asociadas, principalmente, a las redes sociales de Facebook de cada museo, durante el mes de febrero 2018 (28 días consecutivos). Con el fin de evaluar las plataformas web 2.0, se consideraron dos criterios de evaluación la comunicación y la eficacia de las web, propuestos en el trabajo de Tuñez, et al. (2016), los cuales fueron 


\section{Gómez Edwin - Preciado Solange - Palma Verónica - Chumaña Tania - Arrivillaga Jazzmín \\ Monitoreo rápido del uso de plataformas turísticas asociada a espacios de aprendizaje-comunicación cultural: caso de estudio museos (Ecuador)}

modificados parcialmente para la presente investigación en relación con las variables seleccionadas para el estudio dentro de cada criterio (Tabla 1 y 2 ).

En este sentido, se evaluó la comunicación de la Web 2.0 con base en las siguientes variables: presencia (número de seguidores y publicaciones); crecimiento (número de seguidores nuevos durante el periodo de estudio, 28 días); actividades (se refiere al número de publicaciones como indicador de desempeño); nivel de servicio (respuesta en tiempo que brinda el museo a los usuarios); participación (número de "me gusta", número de comentarios y número de contenidos compartidos).

Por otro lado, para la evaluación de la eficacia de las plataformas, se consideraron las siguientes variables:

- Variable accesibilidad, indicador de idioma de la web (1pts= un solo idioma, $2 \mathrm{pts}=$ idioma local + segundo idioma) + accesibilidad web para personas con discapacidad $(0=$ no tiene, $1 \mathrm{pts}=$ al menos un tipo de discapacidad, $2 \mathrm{pts}=2$ tipos de discapacidad $3=$ tres tipos de discapacidad, $4 p t s=$ certificación de accesibilidad digital).

- Variable narrativa digital: incorporación de recursos multimedia como video, fotografía, audio, gráficos interactivos, video en vivo y notas-documentos. Cada indicador presente implica un valor de 1 pts.

- Variable contenidos e información. Indicadores asociados: Oferta turística cultural (ubicación geográfica dentro de la ciudad de Quito, y tipo de museo y colecciones), información para la planificación de la visita al museo (horarios, costo de entradas, paquetes por grupo de visitantes, reserva y pago online, normativas de ingreso al museo, información sobre ¿qué hacer?, ¿cómo llegar?, calendario de eventos), información de servicios complementarios (alojamiento, alimentación, parqueadero, venta de entradas para otros museos o venta de boletos integrales para visitar museos, contratación de guías turísticos, link agencias de viajes involucradas en la promoción de los museos), seguridad (contacto de quejas, contactos de emergencias). Valor de cada indicador es de 1 pts.

- Variable de recursos digitales. Indicador: mapas y folletos digitales, visión 360, realidad aumentada, guías y audio de visita promocional, juegos online asociados al museo, centro de reserva online, herramientas digitales para planificar la visita. Valor de cada indicador 1 pts.

- Variable movilidad remota: versión de la web para dispositivo móvil y aplicaciones asociada a los museos Valor de cada indicador es de 1 pts.

- Variable interactividad de la plataforma del museo. Indicador existencia de redes sociales (Facebook, Twitter, Instagram, YouTube), atención al cliente online, comunidades virtuales, correo electrónico, encuestas, foros, opiniones, chat, posibilidad de publicar contenidos, posibilidad de valorar contenidos ("me gusta"), posibilidad de compartir información, suscriptores, seguidores. Valor de cada indicador 1 pts.

\section{RESULTADOS}

\section{Perfil del visitante/usuario de la plataforma tecnológica de los museos}

En función de las cuatro variables demográficas seleccionadas, los resultados evidencian a nivel de género, que la proporción de sexo de los usuarios de las plataformas es de 1:1. Sin embargo, se observa un $8 \%$ de usuarios pertenecientes al género "otros". En relación con la variable procedencia, la mayor proporción de usuarios son visitantes residentes de la Ciudad de Quito (88\%), pero existe una 


\section{Gómez Edwin - Preciado Solange - Palma Verónica - Chumaña Tania - Arrivillaga Jazzmín \\ Monitoreo rápido del uso de plataformas turísticas asociada a espacios de aprendizaje-comunicación cultural: caso de estudio museos (Ecuador)}

población visitante de turistas (12\%) que usan las plataformas de los museos de la red del Centro Histórico de Quito, al menos confines de visita.

En relación con la variable nacionalidad, el $45 \%$ son ciudadanos ecuatorianos, mientras el $55 \%$ son extranjeros de nacionalidad: venezolana (33\%), colombiana $(10 \%)$, peruana (4\%), chilena (2\%), Otros (6\%, argentinos y españoles). El $12 \%$ de los visitantes turistas son de las nacionalidades: venezolanos, argentinos y españoles.

Respecto a la variable estructura de edades, se observa una estratificación de esta variable en tres subpoblaciones o segmentos de visitantes-usuarios de las plataformas tecnológicas. Grupo 1) representado por el $49 \%$ de la población entre edades de 16-26 años, Grupo 2) entre 27-37 años representando el 35\% de la población y Grupo 3) entre 38-50 años representando el $16 \%$ de los visitantes durante el periodo de la evaluación rápida.

\section{Conocimiento-aprendizaje-uso de la plataforma tecnológica de los museos}

- Conocimiento de las plataformas tecnológicas de la red de museos: los resultados indican que el $70 \%$ de los visitantes de los museos evaluados conocen las plataformas para acceder a cada museo.

- Frecuencia de uso de la plataforma tecnológica de los museos: con relación a la frecuencia de uso de las plataformas, el 38\% de los usuarios-visitantes usan las plataformas anualmente, el $32 \%$ utiliza la plataforma de los museos con frecuencia de uso de mensual a diario. Mientras, el 30\% utiliza la plataforma con frecuencia de semanalmente a diario.

- Capacitación para el manejo y uso de la plataforma de los museos: los resultados asociados a esta pregunta muestran que el 95\% de los usuarios no recibió capacitación para manejar y usar la plataforma tecnológica.

- Capacitador para el uso de la plataforma de los museos: los resultados indican, que del $5 \%$ de los usuarios que necesitaron capacitación para manejar y usar la plataforma. El $40 \%$ de los usuarios fueron capacitados por docentes, $20 \%$ por aprendizaje previo en cursos de internet, $20 \%$ por el uso previo de plataformas similares, y solo un $20 \%$ por personal del museo.

- Grado de dificultad al usar las plataformas de los museos: los resultados indican que el $45 \%$ de los usuarios consideran un grado bajo de dificultad al usar la plataforma, sin embargo, el $55 \%$ de los usuarios consideran que existe un grado de dificultad significativo al usar las plataformas de museos para la búsqueda de una información específica.

- Calificación de las herramientas virtuales de la plataforma de museos: Los resultados evidencian que el $60 \%$ de los usuarios de las plataformas consideran que las herramientas virtuales son de excelentes a buenas, pero un sector significativo de usuarios, el $40 \%$, cataloga a estas herramientas regulares.

\section{Percepción sobre la plataforma tecnológica de los museos}

Motivo de consulta virtual de las plataformas tecnológicas: el $40 \%$ de los usuarios usa la plataforma solo para consultar horarios de visita y costo de la entrada. Adicionalmente, el $20 \%$ usa la plataforma para revisar el contenido del museo, pero un $40 \%$ tiene otras motivaciones asociadas con información más precisa acerca de la historia del museo y conocimiento específico de búsqueda.

Percepción sobre la calidad de la plataforma tecnológica de la red de museos: Los resultados indican que solo el $60 \%$ de los usuarios de las plataformas consideran que 


$$
\begin{gathered}
\text { Gómez Edwin - Preciado Solange - Palma Verónica - Chumaña Tania - Arrivillaga } \\
\text { Jazzmín } \\
\text { Monitoreo rápido del uso de plataformas turísticas asociada a espacios de } \\
\text { aprendizaje-comunicación cultural: caso de estudio museos (Ecuador) }
\end{gathered}
$$

las mismas son excelentes-muy buenas, mientras, que el resto de los usuarios no tiene una buena percepción sobre la calidad de dichas plataformas asociados a los dos museos analizados.

\section{Satisfacción del usuario/visitante derivada del uso de la plataforma tecnológica}

Grado de satisfacción en relación con el uso de la plataforma de la tecnológica de la red de museos: el $85 \%$ de los usuarios de las plataformas tecnológicas de los museos manifiestan una satisfacción alta a bastante satisfecho con la plataforma tecnológica en función del uso de esta. Sin embargo, el 15\% están insatisfechos con la plataforma.

Beneficio obtenido del uso de las plataformas: el $68 \%$ de los usuarios se beneficia porque obtiene algún tipo de información en relación con lo que busca, un $20 \%$ manifiesta la facilidad de obtener la información como beneficio, el $5 \%$ se beneficia de poder realizar reservas en línea; sin embargo, solo el 7\% manifiesta obtener beneficios de aprendizaje efectivo sobre alguna temática de interés asociada al museo.

Tipo de comentarios-opiniones-quejas que han comunicado los usuarios-visitantes directamente en la plataforma: en un $100 \%$ de los visitantes-evaluados manifestaron que no han realizado ningún tipo de acción comunicativa interactiva y participativa con la plataforma de los museos MCS y MC.

\section{Web}

\section{Sitios web}

Ambos museos son promocionados desde la red de la Fundación de Museos de la ciudad (http://www.museosquito.gob.ec), y solo el Museo Casa Sucre cuenta en la actualidad con la publicación de sus propios contenidos, pero la información forma parte de la red de Museos de la defensa (http://www.museosdefensa.gob.ec), (Figs. 2 y 3).

Las web, son principalmente de lectura, en donde el contenido es la base de la consulta. En este punto, el contenido de la web del Museo de la Casa Sucre es más dinámico, cuentan con una aplicación para móvil "Ilamada" visión 360, ventanas con dinamismo, en comparación con la web de la Fundación de Museo de la Ciudad, que solo tiene información de contenido por museo con base en la planificación de la visita. Las web solo tienen navegadores de texto, páginas estáticas con interacción solo vía contacto, principalmente mediante el correo electrónico, con baja actualización de la información, y poco contenido de aprendizaje efectivo. 


\section{Gómez Edwin - Preciado Solange - Palma Verónica - Chumaña Tania - Arrivillaga Jazzmín \\ Monitoreo rápido del uso de plataformas turísticas asociada a espacios de aprendizaje-comunicación cultural: caso de estudio museos (Ecuador)}
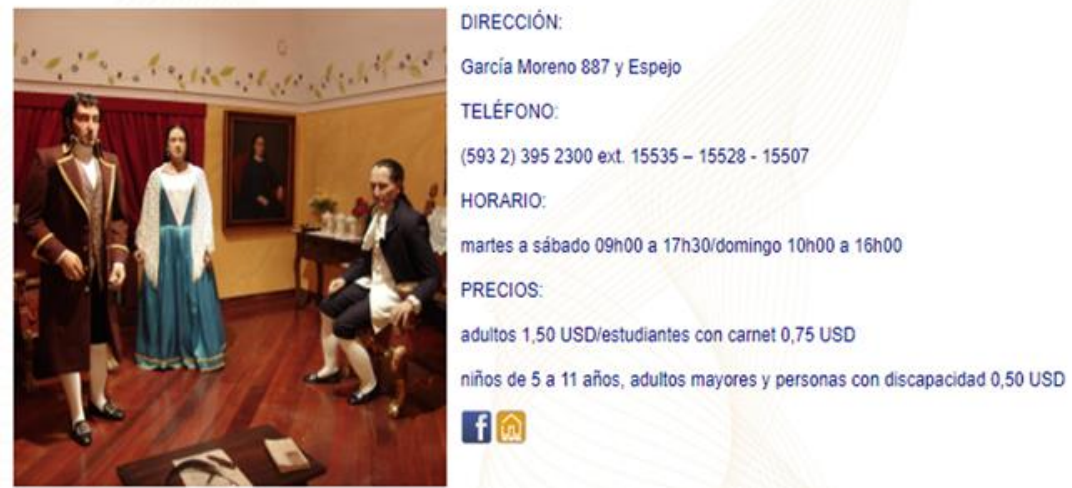

El "Museo de Arte e Historia Alberto Mena Caamaño" fue creado el 28 de mayo de 1957 a partir del fondo donado por Alberto Mena Caamaño. En 1970 el museo integró a la exposición permanente una sala sobre la masacre del 2 de Agosto de 1810. Esta escena fue realizada en cera por el artista Alexander Barbieri, quien tomó como modelo un cuadro pintado a inicios del siglo XX por César Villacrés titulado 'El Sacrificio de Quiroga". A partir de entonces este espacio ha sido popularmente conocido como "Museo de Cera". Actualmente el Museo Alberto Mena Caamaño cuenta con una exposición permanente que se titula "De Quito al Ecuador (1736 - 1835)", 4 salas de exposición temporal, un espacio lúdico - educativo, el auditorio "Hugo Alemán' y una variada oferta educativa y cultural para el disfrute de nuestros visitantes.

Fig.2. Imágenes de la Web 1.0 del Museo de Cera desde la plataforma http://www.museosquito.gob.ec.

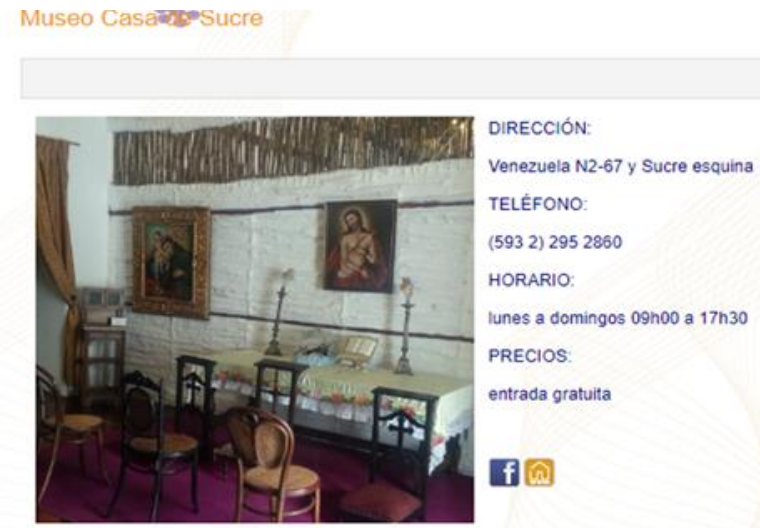

El Museo de la Defensa "Casa de Sucre", es un espacio que pretende mostrar, las formas de configuración de la sociedad quiteña en los albores de la llustración, entre los siglos XVIII y XIX, asi como también develar las relaciones sociales, politicas y económicas, que infuyeron en los procesos de independencia, y la adscripción de la Real Audiencia de Quito al proyecto bolivariano. Como museo de sitio, a través de su recorrido el espectador podrá conocer, como era una casa de estilo colonial, asi como la historia de quienes habitaron este inmueble.

Sư exposición incluye tres temas:

1.- Museo de Sitio (información histórica sobre el inmueble y sus áreas).

2.-Mariana Carcelén y Antonio José de Sucre.

3.- Sucre y Bolivar, hacia un ideal de independencia.

Fig.3. Imágenes de la Web 1.0 del Museo de la Casa Sucre desde la plataforma http://www.museosquito.gob.ec.

\section{Redes sociales}

Actualmente, la Fundación Museos de la Ciudad cuenta con una plataforma web 2.0, mediante el uso principalmente de la red social Facebook (https://www.facebook.com/FundacionMuseosQuito-@FundacionMuseosQuito), pero cuenta con Twitter y YouTube. Los museos que forman parte de fundación en Facebook MUSEO DE LA CIUDAD (MDC), YAKU PARQUE MUSEO DEL AGUA, MUSEO INTERACTIVO DE CIENCIA (MIC), CENTRO DE ARTE CONTEMPORÁNEO (CAC), EL SISTEMA METROPOLITANO DE MUSEOS Y CENTROS CULTURALES 


\section{Gómez Edwin - Preciado Solange - Palma Verónica - Chumaña Tania - Arrivillaga Jazzmín \\ Monitoreo rápido del uso de plataformas turísticas asociada a espacios de aprendizaje-comunicación cultural: caso de estudio museos (Ecuador)}

(SIMMYCC), MUSEO DEL CARMEN ALTO Y CUMANDÁ PARQUE URBANO, dentro de los cuales no se listan los Museos monitoreados en el presente estudio.

El Museo Albero Mena Caamaño (Museo de Cera), cuenta con su propias redes sociales, página Facebook, www.facebook.com/pg/museodeceraMAMC@museoalbertomena, pero el Twitter @EIMetQuito es usado por la red del Centro Cultural Metropolitano como un plataforma común, con fines de planificación de la visita como se señala en la información del museo (Fig. 4). Mientras, el Museo de la Casa Sucre (Museo de la defensa), no cuenta con una página propia, pero existe accesibilidad digital a través de la plataforma de Facebook www.facebook.com/museosdefensa-@museosdefensa, y el Twitter \#museosdeladefensa. Todas las Web 2.0, son plataformas con alto contenido promocional y dirigidas a un público general, sin conglomerados o segmentación según el tipo de usuario, con pocas herramientas de accesibilidad para el aprendizaje histórico cultural mediado por la plataforma en sí.

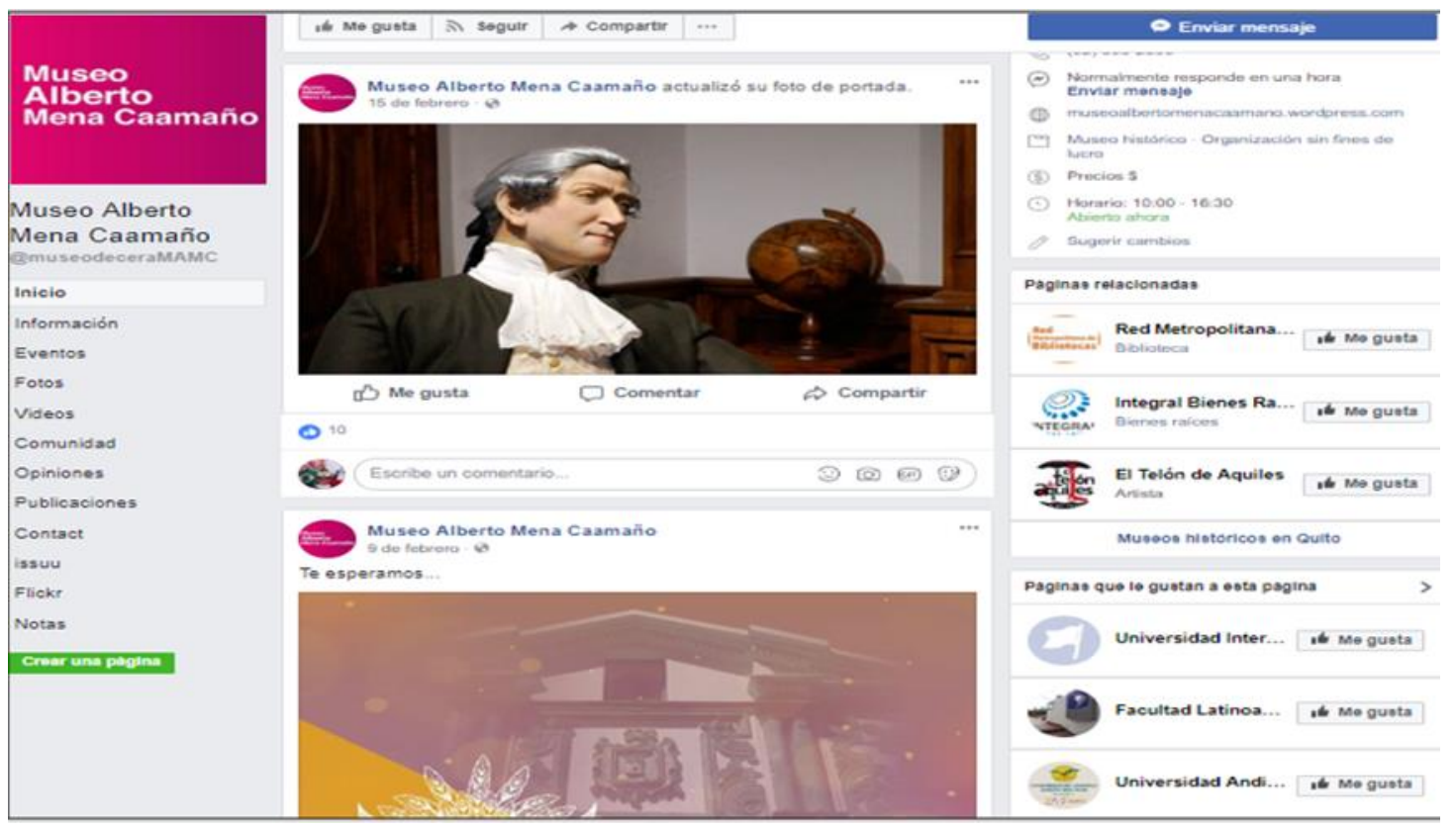

Fig. 4. Web 2.0 Museo Alberto Mena Caamaño (Museo de Cera) plataforma www.facebook.com/pg/museodeceraMAMC.

Con relación a la evaluación de la comunicación Web 2.0 de las plataformas de los museos, los resultados del monitoreo evidencian que la evaluación de los Museos de Cera (MC) y Museo Casa Sucre (MCS), en comparación con los valores obtenidos para la Fundación de Museos de la Ciudad de Quito (FMCQ, usado como referencia), la valoración solo representa del $0-20 \%$ respecto a la evaluación de la comunicación web 2.0 de FMCQ (Tabla 1). Lo que implica una actividad muy baja en la plataforma, que refleja una participación baja por parte de los usuarios.

Adicionalmente, solo se evidencia en la plataforma un comentario en el ítem de opinión del Facebook MC (fecha 03 de febrero del 2018) en donde un usuario señala su grado de satisfacción en relación con una visita al museo: "Me gustó muchísimo la información y todo el lugar en general, los personajes excelentes parecían de verdad muy reales", pero este comentario no generó ninguna actividad o acción de comunicación interactiva por parte de MC u otro usuario-seguidor. En contraste con el Facebook MCS, no se evidencia en la plataforma tecnológica de los Museos de la Defensa ninguna opinión o comentario por parte de los usuarios desde el año 2017, a 


\section{Gómez Edwin - Preciado Solange - Palma Verónica - Chumaña Tania - Arrivillaga Jazzmín \\ Monitoreo rápido del uso de plataformas turísticas asociada a espacios de aprendizaje-comunicación cultural: caso de estudio museos (Ecuador)}

pesar de existir "me gusta" y algunas acciones de compartir con otros usuarios de la red social. Lo que evidencia que no hay participación en pro de la construcción del conocimiento asociado a contenidos publicados.

\begin{tabular}{|c|c|c|c|c|}
\hline Variable & Indicador & $\begin{array}{l}\text { Valoración } \\
\text { FMCQ }\end{array}$ & $\begin{array}{l}\text { Valoración } \\
\text { MC }\end{array}$ & $\begin{array}{l}\text { Valoración } \\
\text { MCS }\end{array}$ \\
\hline Presencia & N. ${ }^{\circ}$ seguidores totales & 21593 & 2346 & 1419 \\
\hline Crecimiento & N. ${ }^{\circ}$ seguidores nuevos & 20 & 0 & 0 \\
\hline Actividades & N. ${ }^{\circ}$ de publicaciones & 50 & 6 & 10 \\
\hline Servicio & $\begin{array}{l}\text { Tiempo promedio de } \\
\text { respuesta }\end{array}$ & $24 \mathrm{~h}$ & minutos & $i$ \\
\hline Participación & N. ${ }^{\circ}$ total "me gusta" & 21608 & 2346 & 1417 \\
\hline Participación & N. ${ }^{\circ}$ "me gusta" & 207 & 28 & 14 \\
\hline Participación & N. ${ }^{\circ}$ de comentarios & 11 & 0 & 0 \\
\hline Participación & N. ${ }^{\circ}$ de compartir & 81 & 5 & 4 \\
\hline Participación & $\begin{array}{l}\mathrm{N} .{ }^{\circ} \quad \text { publicaciones } \\
\text { visitantes }\end{array}$ & 0 & 0 & 0 \\
\hline Participación & $\mathrm{N} .^{\circ}$ opiniones web & 0 & 1 & 0 \\
\hline
\end{tabular}

Tabla 1. Indicadores para la evaluación de la comunicación web 2.0 (Facebook). No= número, $F M C Q=$ fundación de museos de la ciudad Quito, $M C=$ Museo de Cera, MCS $=$ Museo Casa Sucre. $i=$ no se registra en la red social/se desconoce.

La evaluación de la eficacia total de la plataforma web 2.0, evidencia una relación de valoración jerárquica de menor a mayor, Museo Casa Sucre < Museo de Cera < Fundación Museo de la Ciudad. En donde se observa una diferencia de apenas un punto con relación a la ponderación total, entre la plataforma web 2,0 del Museo de Cera vs la Fundación del Museo de la Ciudad. Evidenciándose falencias similares entre estos dos grupos de museos, con relación a la narrativa digital, recursos digitales, movilidad remota y algunos indicadores de participación. Siendo el Museo Casa Sucre el que presenta más debilidades en su plataforma web 2.0 (Tabla 2).

\begin{tabular}{lllll}
\hline Variable & Indicador & $\begin{array}{l}\text { Valoración } \\
\text { FMCQ }\end{array}$ & $\begin{array}{l}\text { Valoración } \\
\text { MC }\end{array}$ & $\begin{array}{l}\text { Valoración } \\
\text { MCS }\end{array}$ \\
\hline Accesibilidad & Idioma & 1 & 1 & 1 \\
Accesibilidad & Discapacidad & 0 & 0 & 0 \\
Narrativa digital & Videos & $1^{*}$ & 1 & 1 \\
& Fotografías & $1^{*}$ & 1 & 1 \\
& Audios & 1 & 1 & 0 \\
& Gráficos & 0 & 0 & 0 \\
& Video en vivo & 0 & 0 & 0 \\
Contenido & Notas- & 1 & 0 & $1^{*}$ \\
\hline
\end{tabular}


Gómez Edwin - Preciado Solange - Palma Verónica - Chumaña Tania - Arrivillaga

Monitoreo rápido del uso de plataformas turísticas asociada a espacios de aprendizaje-comunicación cultural: caso de estudio museos (Ecuador)

\begin{tabular}{|c|c|c|c|c|}
\hline \multicolumn{5}{|l|}{ información } \\
\hline & Tipo museo & 1 & 1 & 1 \\
\hline & Tipo colección & 1 & 1 & 1 \\
\hline & $\begin{array}{l}\text { Planificación } \\
\text { visita }\end{array}$ & 1 & 1 & 0 \\
\hline & $\begin{array}{l}\text { Servicios } \\
\text { complementarios }\end{array}$ & 1 & 0 & 0 \\
\hline & Seguridad & 0 & 0 & 0 \\
\hline & Educativo & 1 & 0 & 1 \\
\hline \multirow[t]{7}{*}{ Recursos digitales } & $\begin{array}{l}\text { Mapas y folletos } \\
\text { digitales }\end{array}$ & $1^{*}$ & 1 & 1 \\
\hline & Visión 360 & 0 & 0 & 0 \\
\hline & $\begin{array}{l}\text { Realidad } \\
\text { aumentada }\end{array}$ & 0 & 0 & 0 \\
\hline & $\begin{array}{l}\text { Guía y audio } \\
\text { visita }\end{array}$ & 0 & 0 & 0 \\
\hline & Juegos online & 0 & 0 & 0 \\
\hline & $\begin{array}{l}\text { Centro de } \\
\text { reservas online }\end{array}$ & 0 & 1 & 0 \\
\hline & $\begin{array}{l}\text { Planificación } \\
\text { visita digital }\end{array}$ & 0 & 0 & 0 \\
\hline \multirow[t]{2}{*}{ Movilidad remota } & Dispositivo móvil & 0 & 0 & 0 \\
\hline & $\begin{array}{ll}\text { Diseño } & \text { de } \\
\text { aplicaciones }\end{array}$ & 0 & 0 & 0 \\
\hline \multirow[t]{15}{*}{ Interactividad } & Facebook propia & 1 & 1 & 0 \\
\hline & Link Twitter & 1 & 0 & 0 \\
\hline & Link Instagram & 0 & 0 & 0 \\
\hline & Link YouTube & 1 & 0 & 0 \\
\hline & $\begin{array}{l}\text { Atención cliente } \\
\text { online }\end{array}$ & 0 & 0 & 0 \\
\hline & $\begin{array}{l}\text { Comunidades } \\
\text { virtuales }\end{array}$ & $1^{*}$ & 1 & 1 \\
\hline & $\begin{array}{l}\text { Correo } \\
\text { electrónico }\end{array}$ & 1 & 1 & 0 \\
\hline & Encuestas & 0 & 0 & 0 \\
\hline & Foros & 0 & 0 & 0 \\
\hline & Opiniones & 1 & 1 & 1 \\
\hline & Chat & 0 & 0 & 0 \\
\hline & $\begin{array}{l}\text { Publicación } \\
\text { contenidos }\end{array}$ & $1^{*}$ & 1 & 1 \\
\hline & $\begin{array}{l}\text { Valoración } \\
\text { contenida }\end{array}$ & $1^{*}$ & 1 & 1 \\
\hline & $\begin{array}{l}\text { Posibilidad } \\
\text { compartir }\end{array}$ & $1^{*}$ & 1 & 1 \\
\hline & $\begin{array}{l}\text { Suscriptores- } \\
\text { seguidores }\end{array}$ & $1^{*}$ & 1 & 1 \\
\hline Total, Valoración & & 21 & 19 & 13 \\
\hline
\end{tabular}




\section{Gómez Edwin - Preciado Solange - Palma Verónica - Chumaña Tania - Arrivillaga Jazzmín \\ Monitoreo rápido del uso de plataformas turísticas asociada a espacios de aprendizaje-comunicación cultural: caso de estudio museos (Ecuador)}

Tabla 2. Indicadores para la evaluación de la eficacia web 2.0. FMCQ= Fundación de Museos de la Ciudad Quito, MC= Museo de Cera, MCS= Museo Casa Sucre. $1^{*}=$ mayor número de publicación y visibilidad de la actividad.

\section{DISCUSIÓN}

En líneas generales el perfil del usuario de las plataformas tecnológicas indica que el usuario promedio es residente de la Ciudad de Quito, principalmente extranjero, con tendencia a equidad de género y generacionalmente es adaptado o nativo digital. Estos datos evidencian el solapamiento del turismo doméstico y el turismo residencial. Sin embargo, se observa en menor proporción el turismo intrarregional por ser la mayoría de los turistas suramericanos (OMT, 2017)

Lo que indica que el género, edad, nacionalidad y procedencia del visitanteusuario no es una limitante para el uso de la plataforma, las cuales están construidas en el idioma español. Estos resultados acerca del uso de un idioma, el español, es concordante con los museos españoles, conceptualizándose a los museos iberohispánicos con este formato de un solo idioma de comunicación (Asensio et al., 2012a)

El monitoreo rápido evidencia que las plataformas de los museos analizados tienen como objetivo único informar, con contenido hacia horarios, dirección, costo, reserva, compra. Estas características permiten clasificar las plataformas del Museo Casa de Sucre y Museo de Cera, como del tipo plataforma 1.0 similar a otros museos con valor patrimonial (Asensio et al., 2012a; 2012b, Altamirano, 2016).Por lo que nuestros resultados permiten aceptar la hipótesis de trabajo planteada.

En relación con la variable conocimiento de las plataformas, mayoritariamente los visitantes-usuarios utilizan las plataformas con una frecuencia de uso promedio mensual y de forma autodidacta, lo que refleja una identidad digital, ya en su mayoría los visitantes son usuarios digitales y usuario de museo tipo solicitante de información (Gallegos y Taboada, 2014).

En general, los usuarios consideran que las plataformas tienen un grado medioalto de dificultad al usarse en el momento de buscar información específica e hipervínculos, pero con una calidad buena-excelente de la web en sí. Lo cual se correlaciona con el conocimiento que tienen los visitantes-usuarios sobre las plataformas de los museos evaluados y la frecuencia alta de uso por parte de los mismos usuarios. Adicionalmente, de forma indirecta esto tiene implicaciones positivas en relación con las visitas presenciales recibidas en ambos museos, ya que tienen alta afluencia de visitantes. Siendo, estos resultados explicados sobre la base de la calidad y trayectoria de los museos, así como a su compromiso por la difusión del turismo histórico cultural en la Ciudad de Quito (Sanz y Gonzalo, 2017).

Sin embargo, hay un porcentaje de usuarios que no son autodidactas a pesar de pertenecer a intervalos de edades categorizados como "nativos digitales", y han sido capacitados por sus docentes, derivado en algunos casos a su desconocimiento sobre el uso de plataformas en internet y en otros a su desinterés por los contenidos culturales antes de realizar la primera visita presencial al museo. Estos datos indican, de forma indirecta, la importancia de plataformas en los procesos de enseñanzaaprendizaje y en la activación de las visitas en la Ciudad de Quito, lugar de residencia del $88 \%$ de los visitantes-usuarios.

Los usuarios en su mayoría están satisfechos y obtienen beneficios de las plataformas. Sin embargo, los resultados indican que el aprendizaje no es efectivo empleando las plataformas Web de los museos, es decir no permite la construcción de conocimiento o saberes respecto a una temática cultural específica, porque la plataforma está dirigida a un público en general, y no esta estratificada o dirigida a conglomerados. Por lo que la plataforma no cumple el rol de promoción dirigida, a la 


\section{Gómez Edwin - Preciado Solange - Palma Verónica - Chumaña Tania - Arrivillaga Jazzmín \\ Monitoreo rápido del uso de plataformas turísticas asociada a espacios de aprendizaje-comunicación cultural: caso de estudio museos (Ecuador)}

vez que los contenidos son predeterminados y no actualizados o dinámicos (Asensio et al., 2012a).

Siendo necesario rediseñar a la Web y apuntar en un segundo nivel hacia el mejoramiento de la plataforma 2.0, es decir el uso de redes sociales de forma eficaz, con la finalidad de generar mejores herramientas para el uso del espacio con hipervínculos, y así mejorar el contenido educativo, para incrementar el uso de las plataformas de museo como espacios de aprendizaje. Lo cual promovería un espacio más interactivo y participativo en el área de cultura conocimiento-aprendizaje por parte del visitante-usuario del espacio de contenido generado por el museo, con más visión de construir capital y participación social, ya que el usuario de este tipo de plataformas en Ecuador específicamente utiliza los espacios de las redes sociales, que son recomendados o compartidos por usuarios conocidos (Forteza, 2012; MengualAndrés, 2015, Ozzane et al. 2017).

Por otro lado, estas potenciales mejoras tecnológicas asociadas no a los usuarios sino a los museos como institución u organización, deben ir acompañada de otras estrategias que permitan una mayor inclusión de visitantes-usuarios de plataformas tecnológicas en el Ecuador. Además, se debe involucrar el desarrollo de competencias digitales que permita adquirir una actitud crítica y reflexiva en relación al tipo de información y lectura de la misma en la Web 2.0, apuntando al desarrollo de habilidades de lectura de textos hipertextual, derivado a las características de interactividad y de retroalimentación que debe tener una Web 2.0, con base en principalmente a su comunicación multimedia, audiovisual y fotográfica de calidad, lo que permitiría educar a los potenciales usuarios de las redes, para que sean más participativos y puedan generar opiniones y comentarios directamente en las plataformas tecnológicas como demanda a sus exigencias y necesidades (Mendoza, 2008; Área y Pessoa, 2012; Galindo, 2015).

Esto involucra la implementación de políticas públicas en pro de un nuevo modelo de sociedad ecuatoriana, aprovechando el valor histórico y patrimonial en el país, para conceptualizarse como una sociedad de conocimiento, en donde los museos juegan un rol clave en la formación de un capital cultural ciudadano (Santos, 2012).

Por lo cual, como meta inmediata los museos deben mostrar una visibilidad $100 \%$ activa, creando identidad de museo, estrategias y planes de comunicación, herramientas de evaluación en pro de su autoevaluación y supervisión, tales como el monitoreo, seguimiento y evaluación, mantener la actividad mediante las actualizaciones recurrentes y las agendas de actividades vía web para visibilizar el museo, atender las peticiones de información y comentarios de los usuarios, segmentar la información según el tipo de visitante con base en el conocimiento previo de la audiencia virtual con participación de la audiencia selectiva, para estar más cerca del visitante-usuario y no solo como estrategia publicitaria, lo que apuntaría hacia una eficiente retroalimentación para generar información (Asencio et al., 2012b). Apuntar hacia servicios en línea y museos virtuales o digitales, aplicaciones móviles, imágenes 360 , incorporar audio guías, realidad virtual y aumentada en pro de visitas virtuales como elementos de punta para compartir el conocimiento cultural en pro de un turismo cultural 2.0.

Mientras, a corto plazo, los museos deberán ser más participativos y adaptarse a las exigencias de los visitantes-usuarios que retroalimentan la Web 2.0, para generar una comunicación $100 \%$ dirigida a las personas, visitantes, turistas, en donde el museo sea conceptualizado como un producto cultural ajustable a las exigencias de la demanda cultural con una apariencia personalizada y geolocalizada, y enfatizándose el intercambio de opiniones, recomendaciones y experiencia en la comunidad de usuarios, lo que se enfoca en la emociones como la clave de ese nuevo marketing de contenidos y del posicionamiento desde contenidos multimedia, apoyándose en 


\section{Gómez Edwin - Preciado Solange - Palma Verónica - Chumaña Tania - Arrivillaga Jazzmín \\ Monitoreo rápido del uso de plataformas turísticas asociada a espacios de aprendizaje-comunicación cultural: caso de estudio museos (Ecuador)}

buscadores tradicionales y buscadores de web profunda, para incrementar el tráfico de visitas de las páginas. Buscando monitorear a la audiencia de las redes sociales empleando herramientas estadísticas y de manejo de base de datos de usuarios con fines de prospección, en donde los dispositivos móviles pueden jugar un rol clave en la interacción, y específicamente marca un cambio hacia una participación, características actuales de la comunicación con base en el uso de plataformas de tipo web 3.0 (Abad et al., 2010: Asensio et al., 2012b).

En general, el uso de plataformas de redes sociales evaluadas, han permitido incrementar el número de visitantes-usuario en los museos analizados, pero la construcción del conocimiento cultural ciudadano en sí no ha incrementado de forma correlativa. Por lo que el valor patrimonial, histórico cultural de los dos museos estudiados no ha podido ser divulgado adecuadamente. Al igual que la mayoría de los museos que han sido evaluados en otros países, lo que evidencia que por sí misma una red social no contribuye al aprendizaje y comunicación cultural (Asensio et al. 2012b).

La situación actual de los museos MCS y MC requerirá de estrategias nuevas, y de visiones multidisciplinarias, asociadas a otros campos emergentes en el Ecuador que integren espacios públicos, aprendizaje y cultura, como el turismo educativo (Yanes 2007; Orduna y Urpí, 2010) y la educación tecnológica en pro de la gestión del patrimonio cultural y de la cultura ciudadana para apoyar el rol de los museos en la gestión del conocimiento. Lo que probablemente permitirá a largo plazo, utilizar las herramientas tecnológicas de la Web 4.0 como sistemas operativos inteligentes (Escaño, 2010).

\section{CONCLUSIONES}

El monitoreo rápido representa una herramienta útil de evaluación periódica y de intervención de procesos para la evaluación de cumplimiento de actividades y acciones que ejecutan los museos en un tiempo determinado dentro de las plataformas tecnológicas con base en opiniones de usuarios, indicadores y con un esfuerzo de muestreo bajo ajustado a metodologías cualitativos de estudios de casos. En la presente investigación, la evaluación rápida respecto a las redes sociales tipo Facebook evidenció que los Museos de Cera y Museo Casa Sucre necesitan mejoras sustanciales en sus plataformas tecnológicas tipo Web 2.0, con la finalidad de aumentar su competitividad, y en especial su visibilidad como museo interactivo y participativo atendiendo a las demandas de un visitante-usuario mayoritariamente nativo digital.

\section{BIBLIOGRAFÍA}

Abad, M., de la Casa, J., y Lorenzo, F. (2010). La Comunicación corporativa de los museos en España a través de la comunicación 3.0: cuatro años de la evolución comunicativa em la Red. In I/ Congreso internacional comunicación (Vol. 3). 315pp. Recuperado de http://giovannipf.260mb.net/comunicacioncorporativa.pdf

Alfonso, M. (2003). El patrimonio cultural como opción turística. Horizontes antropológicos, 9(20),97-115. http://www.scielo.br/scielo.php?pid=S010471832003000200006yscript=sci artt extytlng=pt 

Gómez Edwin - Preciado Solange - Palma Verónica - Chumaña Tania - Arrivillaga

Monitoreo rápido del uso de plataformas turísticas asociada a espacios de aprendizaje-comunicación cultural: caso de estudio museos (Ecuador)

Altamirano, V. (2017). Comunicación Turística 2.0. Análisis comparativo de y los países de Iberoamérica (Tesis doctoral). Universidad Santiago de Compostela. 619pp. Recuperado de https://scholar.google.es/scholar?hl=esyas_sdt=0\%2C5yq=COMUNICACl\%C3\% 93N+TUR\%C3\%8DSTICA+2.0.+AN\%C3\%81LISIS+COMPARATIVO+DE+ECUA $\mathrm{DOR}+\mathrm{Y}+\mathrm{LOS}+\mathrm{PA} \% \mathrm{C} 3 \% 8 \mathrm{DSES}+\mathrm{DE}+\mathrm{IBEROAM} \% \mathrm{C} 3 \% 89 \mathrm{RICAybtnG}=$

Altamirano, V., y Túñez, M. (2016). Promoción y difusión turística de los países de Iberoamérica a través de los medios sociales. International Journal of Information Systems and Tourism (IJIST), 1(1), 76-90. www.ijist-tourism.com

Asensio, M., Fernández, H., y lbáñez, A. (2012a). Análisis de web de museos desde la perspectiva del visitante En: Actas del Congreso ICOFOM: empoderar al visitante. Túnez, noviembre, 2012 ISS 41, pp 62-124.

Asensio, M., Fernández, H., Cuenca, J., Fontal, O. e Ibáñez Etxeberria, A. (2012b). Una reflexión sobre Web, museos y turismo cultural a partir de un estudio cualitativo de indicadores expertos. En: Asensio, Ibáñez, Caldera, Asenjo, y Castro (Eds.). Series Iberoamericanas de Museología. Vol. 89-107.

Area, M. y Pessoa, M. (2012). De lo sólido a lo líquido: las nuevas alfabetizaciones ante los cambios culturales de la Web 2.0. Comunicar, 38, 13-20. Doi: http://dx.doi.org/10.3916/C38-2012-02-01

Basulto, O., y Taboada-de-Zúñiga, P. (2014). Relevancia de las NTIC'S en el turismo cultural/museos. Perspectiva hermenéutica en el mundo contemporáneo. PASOS. Revista de Turismo y Patrimonio Cultural, 12(4),859874.

Cabezuelo, F. y Martínez, F. (2010). Interactividad Revisión conceptual y contextual. Revista Icono 14, 8 (1), 9 - 21. doi: 10.7195/ri14.v8i1.277

Campos, F. (2008). Las redes sociales trastocan los modelos de los medios de comunicación tradicionales. Revista Latina de Comunicación Social (63), 287 293. Recuperado

de http://www.ull.es/publicaciones/latina/_2008/23_34_Santiago/Francisco_Campos. html

Caro, J., Luque-Gil, A., y Zayas-Fernández, B. (2014). Aplicaciones tecnológicas para la promoción de los recursos turísticos culturales. XVI Congreso de Tecnologías de la Información Geográfica, 25,26 y 27 de junio de 2014. 938-946.

Castillo, M. (2012). Tendencias en la Gestión del Conocimiento Cultural: Museos Virtuales (Tesis de Maestría). Universidad de Salamanca (España). Departamento de Biblioteconomía y Documentación. 94p. Recuperado de https://gredos.usal.es/jspui/bitstream/10366/116300/1/TFM CastilloAlfaro MGua dalupe.pdf 

Gómez Edwin - Preciado Solange - Palma Verónica - Chumaña Tania - Arrivillaga

Monitoreo rápido del uso de plataformas turísticas asociada a espacios de aprendizaje-comunicación cultural: caso de estudio museos (Ecuador)

Celorrio, I. (2015). La difusión del museo en el entorno digital: nuevos recursos tecnológicos y online (Tesis de pregrado). Universidad de Valladolid. 55p. Recuperado de http://uvadoc.uva.es/bitstream/10324/14103/1/TFG-N.331.pdf

del Río Castro, N. (2011). Museos y redes sociales, más allá de la promoción. Redmarka: revista académica de marketing aplicado, 7(3), 111-125,

Escandón, P. (2016). Análisis de los sitios Web de los museos de la Ciudad de Quito. Recuperado de https://minerva.usc.es/xmlui/handle/10347/14924

Escaño, C. (2010). Hacia una educación artística 4.0. Arte, Individuo y Sociedad, 22(1),135-144.

http://www.redalyc.org/html/5135/513551278010/

Recuperado

de

Galindo, M. (2015). Lectura crítica hipertextual en la web 2.0. Revista Electrónica" Actualidades Investigativas en Educación", 15(1). Recuperado de http://www.educoas.org/portal/La Educacion Digital/laeducacion 145/en/articles Roberto ApariciEN.pdf

Gómez, C. (2013). Los museos virtuales como espacios para el aprendizaje. Virtualis, 4(8), 35-43. Recuperado de http://aplicaciones.ccm.itesm.mx/virtualis/index.php/virtualis/article/viewFile/79/65

Gordillo, C. (2014). Museo virtual Manuela Sáenz como aporte a la educación (Tesis de pregrado). Universidad Tecnológica Israel. 44p. Recuperado de http://157.100.241.244/bitstream/47000/1144/1/UISRAEL\%20-\%20EC-DIS\%20\%20378.242\%20-\%20290.pdf

Jurado, G. (2015). Los museos de la ciudad de Quito y su relación con la nueva museología. (Tesis de pregrado). Universidad Central del Ecuador.112p. Recuperado de http://www.dspace.uce.edu.ec/bitstream/25000/6161/1/T-UCE0009-517.pdf

Kuperman, K. (2017). Web 2.0 integrada a un soporte digital para la unión y difusión organizada de la información de los diferentes eventos y exposiciones que los museos de la ciudad de Cuenca (Tesis de pregrado, Universidad del Azuay). 125 pp. Recuperado de http://dspace.uazuay.edu.ec/bitstream/datos/7185/1/13132.pdf

Fernández, I. (2015). El papel de los museos en la sociedad actual: discurso institucional o museo participativo/The Role of Museums in Contemporary Society: Institutional Discourse or Participatory Museum. Complutum, 26(2), 3947.

Forteza, M. (2012). El papel de los museos en las redes sociales. Biblios, (48), 31-40.

López, M., Altamirano, V., y Valarezo, K. (2016). Comunicación turística colaborativa 2.0: promoción, difusión e interactividad en las web gubernamentales de Iberoamérica. Revista Latina de Comunicación Social, (71), 249-271.

Mallor, E., González-Gallarza, M., y Fayos, T. (2013). ¿Qué es y cómo se mide el Turismo Cultural? Un estudio longitudinal con series temporales para el caso español. PASOS. Revista de Turismo y Patrimonio Cultural, 11(2), 269-284.

Marshall, B., Cardon, P., Poddar, A., y Fontenot, R. (2013). Does sample size matter in qualitative research?: A review of qualitative interviews in IS research. Journal of Computer Information Systems, 54(1), 11-22. 

Gómez Edwin - Preciado Solange - Palma Verónica - Chumaña Tania - Arrivillaga

Monitoreo rápido del uso de plataformas turísticas asociada a espacios de aprendizaje-comunicación cultural: caso de estudio museos (Ecuador)

Márquez-González, C., y Herrero, J. (2017). Ciudades Patrimonio de la Humanidad de España: la reputación online como elemento de desarrollo turístico. PASOS. Revista de Turismo y Patrimonio Cultural, 15(2), 437-457.

Mateos, S. (2013). Museos y Content Marketing. Hacia un nuevo modelo de generación de contenidos culturales. Zer, 18(4), 13-28. Recuperado de http://dspace.uvic.cat/bitstream/handle/10854/2441/artconlli_a2013_mateos_sant os_museos.pdf?sequence $=1$ yisAllowed $=y$.

Medina, A., y Plaza, A. (2015). El papel estratégico de las tecnologías de la información y las comunicaciones en el turismo. International Journal of Information Systems and Software Engineering for Big Companies (IJISEBC), 2(2), 52-69.

Mendes, G., Biz, A., y Gândara, J. (2013). Innovación en la promoción turística en medios y redes sociales: Un estudio comparativo entre destinos turísticos. Estudios y perspectivas en turismo, 22(1),102-119.

Mendoza, A. (2008). Introducción: textos e intertextos para la formación del lector. En Antonio Mendoza (coord.). Textos entre textos. Las conexiones textuales en la formación del lector (pp. 11-26). Barcelona: Horsori.

Mengual-Andrés, S. (2015). Evaluación de necesidades y expectativas ante la construcción de un espacio interactivo de comunicación, información y aprendizaje histórico-educativo. Revista Complutense de Educación, 26, 141-158.

Miranda, C. (2017). Las redes sociales y su impacto en la promoción turística de la ciudad de Ambato, provincia de Tungurahua (Tesis de pregrado).Universidad Técnica de Ambato. Facultad de Ciencias Humanas y de la Educación. Carrera de Turismo y Hotelería.95p. Recuperado de http://repositorio.uta.edu.ec/bitstream/123456789/25112/1/TESIS\%20CRISTINA \%20MIRANDA.pdf

Monistrol, R., Rovira, C., y Codina, L. (2006). Sitios Web de museos de Cataluña: Análisis y propuesta de evaluación. Hipertext. net, 4(1). Recuperado de https://www.upf.edu/hipertextnet/numero-4/museos.html.

Olsina, L. (1999). Metodología cuantitativa para la evaluación y comparación de la calidad de sitios web (Doctoral dissertation, Facultad de Ciencias Exactas). 274 pp. Recuperado de http://sedici.unlp.edu.ar/bitstream/handle/10915/2475/Documento_completo.pdf?sequenc $\mathrm{e}=1$

Orozco, G. (2005). Los museos interactivos como mediadores pedagógicos. Revista Electrónica Sinéctica, (26), 38-50.

Orduna, G. y Urpí,C. (2010). Turismo cultural como experiencia educativa de ocio, Polis [En línea], 26, 1-20. Recuperado de. URL : http:// polis.revues.org/102

Ozanne, M., Cueva, A., Mattila, A., y Van, H. (2017). An Investigation Into Facebook "Liking" Behavior An Exploratory Study. Social Media+ Society, 3(2),1-12.

Sánchez, E. (2010). Promoción de un destino turístico a través de las redes sociales: el caso de A Coruña en Facebook. Redmarka: revista académica de marketing aplicado, (5), 11-52. Recuperado de

Sanz, R., y Gonzalo, S. (2017). Museos y engagement. La calidad de los espacios web como soporte del compromiso. Revista española de documentación 
Gómez Edwin - Preciado Solange - Palma Verónica - Chumaña Tania - Arrivillaga Jazzmín

Monitoreo rápido del uso de plataformas turísticas asociada a espacios de aprendizaje-comunicación cultural: caso de estudio museos (Ecuador)

científica, 40(1), e116. Recuperado de http://redc.revistas.csic.es/index.php/redc/article/view/970/1475

Santos, E. (2012). Museos y comunicación: algunas reflexiones y consideraciones generales. Asensio, lbañez, Caldera,Asenjo, y Castro (Eds). Series. Iberoamericanas de Museología. Vol. 3. 79-85. 
Gómez Edwin - Preciado Solange - Palma Verónica - Chumaña Tania - Arrivillaga Jazzmín

Monitoreo rápido del uso de plataformas turísticas asociada a espacios de aprendizaje-comunicación cultural: caso de estudio museos (Ecuador)

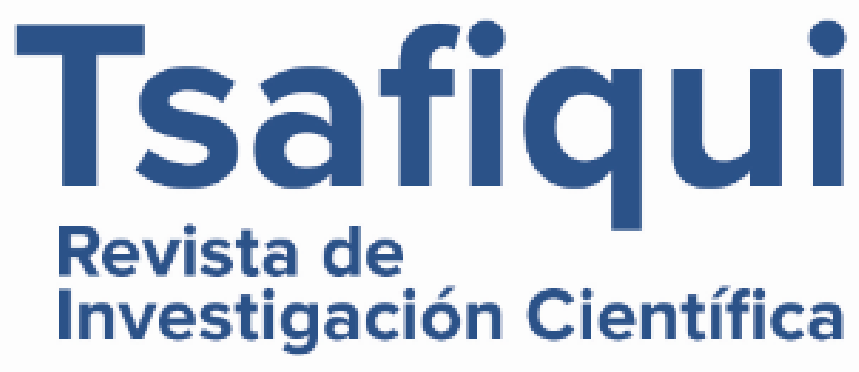

